\title{
A STUDY ON THE SPATIAL INTERPRETATION STRATEGY OF CHANG'AN CITY SITE OF TANG DYNASTY: FROM THE PERSPECTIVE OF CULTURAL ROUTES INTERPRETATION
}

\author{
Y. Yue ${ }^{1}$, L. A. Pezzetti ${ }^{2}$, L. Wang ${ }^{1}$ \\ ${ }^{1}$ Xi'an University of Architecture and Technology, Yanta Road, Xi'an, Shaanxi, China - 2371150513@qq.com \\ ${ }^{2}$ Dept. of Architecture, Built environment and Construction Engineering, Politecnico di Milano, 20133 Milano, MI, Italy - \\ laura.pezzetti@polimi.it
}

KEY WORDS: Interpretation of Cultural Route, Spatial Interpretation Strategy, Chang'an City Site of Tang Dynasty, Cultural Significance

\begin{abstract}
:
Chang'an is the starting point of "Silk Roads: the Routes Network of Chang'an-Tianshan Corridor", which was listed as World Heritage in 2014. Based on the practice and exploration of presentation of the Chang'an City Site of Tang Dynasty in Xi'an, this paper presents a discussion of how to combine the interpretation of cultural routes with the interpretation and presentation of the urban traces under a modern city. Under the pressure of urban development and renewal, it explores the interpretation strategies based on cultural routes, trying to solve the contradictions between the needs of potential heritage conservation and urban development. Moreover, the paper explores contradictions between meanings and values arising among approaches to heritage sites in relation to the urban role as a starting point of the Silk Road. Focusing on the need to actively integrate potential underground ruins into the development plan of the city, the paper extends the notion of "setting" to include the historic urban context and their structuring components. Integrating archaeological and literature materials and based on the heritage value of Chang'an City of Tang Dynasty in the cultural route, the paper attempts to sort out the relationship of inheritance and continuity between the underground city and the modern city patterns. It is argued that such kind of sorting is a key task for spatial interpretation. Furthermore, the spatial interpretation-based strategy for potential sites is recommended as the tool to explore the guiding principles of urban cultural heritage interpretation and land use co-development.
\end{abstract}

\section{INTRODUCTION}

Serving as the main channel of economic and cultural exchanges between the East and the West in ancient times, the Silk Road is widely considered the road of friendship between China and Eurasia. It has experienced a long evolution from its formation, development to decline. The various heritages preserved or continued up to now come to form an incomparable cultural route with unique cultural value. As a world heritage, the elements of the Silk Road include the existing sites, cultural achievements, the unique ecological environment it relies on, and the material and spiritual impetus for its existence.

There is a need for more archaeological and academic studies to clarify the functions, particularly of urban sites, and to link the sites distributed on the cultural routes more clearly through interpretations to the ancient routes to which they were associated.

Chang'an is the starting point of "Silk Roads: the Routes Network of Chang'an-Tianshan Corridor", which was listed as World Heritage in 2014. Chang'an City of Tang Dynasty is the most outstanding representative of the ancient Chinese urban civilization (Dong Jianhong, 2013). In terms of urban planning and construction, it laid the criteria and model of the east Asian cities, thus exerting great influence on other dynasties of China and Japan, Korea, Vietnam and some southeast Asian cities.

Chang'an, the center of imperial Chinese power, is stated in the document, and its main vehicle is a series of palace complexes. In addition, a trail of Buddhist pagodas and large, elaborate cave temples recorded the eastward spread of Buddhism along the Silk Road.

The flourishing Tang Dynasty are desirable. However, rich in material heritage as the city of Chang'an, most of it is buried underground and far away from modern urban life. Sites have been disappearing in large numbers due to the rapid urban development, with only a few having been excavated and protected, yet most being covered by new-born buildings. That situation threatens their survival.

In the selection of the Silk Road World Heritage Site, only the Site of Daming Palace, Great Wild Goose Pagoda, Small Wild Goose Pagoda and Xingjiaosi Pagodas in Chang'an City of Tang Dynasty are included (UNESCO, 2014). The long-term and lagbehind characteristics of archaeological work, as well as the accompanying difficulty in conservation and management, underestimated the value of Chang'an City of Tang Dynasty as the starting point of the Silk Road. Little attention, however, is paid on the issue.

At the same time, it must be noted that: although the Chang'an City pattern of Tang Dynasty is unknown on the ground, there are traces. As is remarked, "where the area belongs to the Chang'an City Site of Tang Dynasty where there must be remains under the ground" (Zhang Jianlin, Gong Guoqiang, 2016). However, these different types of sites are rarely excavated and potential sites tend to be neglected. In addition, the destruction of urban construction and sites is gaining speed, involving unexcavated sites as well as previously excavated and explored ones. In this case, the best way to deal with it is to "present first" and raise the public's awareness and protection awareness of the ruins. However, the unexcavated and 
uncovered sites are difficult to be displayed if only depending on information of the sites themselves.

Under the pressure of urban development and renewal, this paper explores interpretation strategies based on cultural routes, trying to solve the conflicts and contradictions between potential underground heritage conservation needs and urban development. Integrating archaeological and literature materials, based on the heritage value of Chang'an City of Tang Dynasty in the cultural route, this paper attempts to sort out the relationship of inheritance and continuity between the underground city and the modern city patterns. It is argued that such kind of sorting is a key task for spatial interpretation. Furthermore, the spatial interpretation-based strategy for potential sites is recommended as the tool to explore the guiding principles of urban cultural heritage interpretation and land use co-development.

This study is conducted on interpretating the overlying ruins under modern urban city. At the same time, it proposes a guide for the comprehensive interpretation as well as the integration of urban planning and design of the framework of site presentation ideas, on the basis of local conditions to expand its setting for interpretation. As history and culture are continuously recreated for the future, the links to convey comprehension, meanings and values of the underground memory of the city are explored to root regeneration on their presentation enhancement.

\section{CONFLICTS AND CONTRADICTIONS}

Archaeological sites contain material evidence imbued with messages from the past. It plays a fundamental role in developing collective identities. However, each site is an open system, and the understanding of it is always in a process of change and development. Accordingly, the presentation and interpretation of the site is not a one-time or complete process, but a never-ending process. With the development of archaeology and related scientific research, there will be new discoveries, new understanding of its significance and value, and the content and methods of interpretation should be constantly enriched, adjusted and improved with the continuous enrichment and deepening of the achievements.

\subsection{Challenging Situation}

For Chang'an City of Tang Dynasty, only in the late 1950s and early 1960s, the whole site area was explored without being precisely located. For a long time afterwards, the archaeological works were quite passive, fragmented, which were often cooperated with infrastructure construction. The urban built-up area quickly covered the site area, and the survival of most of the sites underground was uncertain. What's more, in the conservation work of the remains of Chang'an City, it failed to reach a unified understanding of its heritage composition, protection area and protection objects for a long time, resulting in the circumstance that protection work are only carried out for the independent protection units, so a large number of remains have not been included in the effective protection.

Combined with previous experience, this passive situation is caused by many factors. From the perspective of planning, it is because of the lack of relevant assessment and prediction for the distribution of potential remains and the lack of planning for the comprehensive conservation of the sites, so the sites found during the construction process are often caught unprepared. The situation gets more complicated when large sites are located in fast-growing cities.

Nowadays, most of the remains of Chang'an City of Tang Dynasty have been overlaid or seriously damaged by modern cities, and only a few important buildings remain on the ground. Some important relics, such as Daming Palace, Qinglong Temple, Xingqing Palace, Daxingshan Temple and Qujiang Lake, have been excavated, protected, developed and utilized. The basic pattern and extent are confirmed by archaeological work, but the details are unknown with traces to follow. Although some sites have carried out presentation works, various factors lead to the lack of integrated consideration based on the overall perspective of the city site, the protection, presentation and utilization work is relatively scattered, and it is difficult to systematically describe the historical memory and connotation of the city.

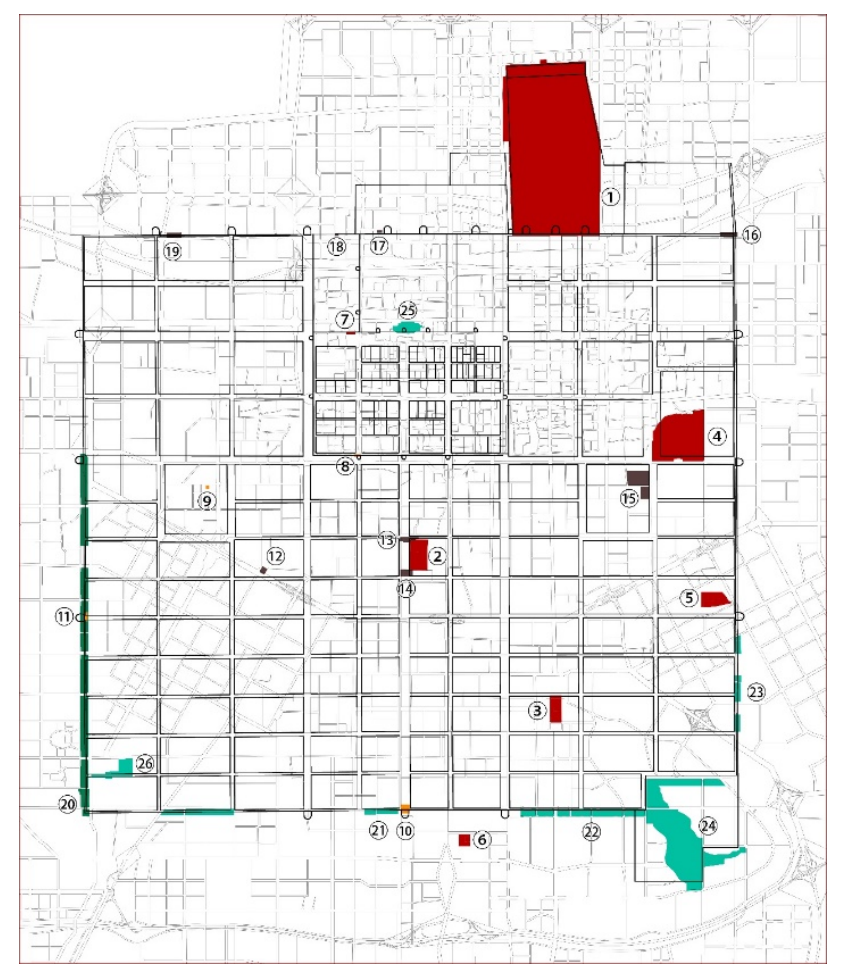

Figure 1. Traces in Chang'an City of Tang Dynasty

(Remains)

\begin{tabular}{|l|l|l|l|}
\hline 1 & Daming Palace & 12 & Ximing Temple \\
\hline 2 & $\begin{array}{l}\text { Small Wild Goose } \\
\text { Pagoda and Jianfu } \\
\text { Temple }\end{array}$ & $\begin{array}{l}13- \\
14\end{array}$ & Anren Block \\
\hline 3 & $\begin{array}{l}\text { Great Wild Goose } \\
\text { Pagoda and Great } \\
\text { Ci'en Temple }\end{array}$ & 15 & East Market \\
\hline 4 & Xingqing Palace & 16 & $\begin{array}{l}\text { Northeast Corner of } \\
\text { the outer city wall }\end{array}$ \\
\hline 5 & Qinglong Temple & $\begin{array}{l}17- \\
19\end{array}$ & North city wall \\
\hline 6 & Yuan Qiu & 20 & West city wall \\
\hline 7 & $\begin{array}{l}\text { Xiwu Temple } \\
\text { the Imperial }\end{array}$ & $\begin{array}{l}21- \\
\text { City wall })\end{array}$ & South city wall \\
\hline 8 & Hangung Gate & 23 & East city wall \\
\hline 9 & West Market & 24 & Qujiang Lake \\
\hline 10 & Mingde Gate & 25 & Chengtian Gate \\
\hline 11 & Yanping Gate & 26 & $\begin{array}{l}\text { Great Zongchi } \\
\text { Temple }\end{array}$ \\
\hline
\end{tabular}

Table 2. Traces in Chang'an City of Tang Dynasty（Remains） 
However, as an important starting point on the cultural route of the silk road, it should not only reflect the value of a few scattered sites on the world heritage list, but also the spatial pattern of sites in the city to become the important carrier for the heritage value, highlighting its important influence of urban planning for the silk road nations.

Therefore, on the one hand, on the basis of archaeological work and effective protection, important patterns and nodes need to be highlighted in the city, a comprehensive conservation, presentation and interpretation system needs to be established, with important cultural influence needs to be enhanced. On the other hand, the strategy of site conservation and utilization combined with urban development still needs to be expanded, and the ways of cultural resources to promote the improvement of social comprehensive benefits still need to be innovated. The work is extremely challenging.

\subsection{Need for Cultural Significance Interpretation}

From the comprehensive interpretation of the Silk Road, cultural routes, as a heritage type, aim to include heritage individuals in an integrated system to enhance their comprehensive value. Cultural routes reflect the evolution of an idea. The significance of associating the heritage of the routes with their background environment and regional scale lies in the construction of a framework with major human history and cultural events as the context. The comprehensive significance is greater than the sum of individual significance, which is not only the characteristics of cultural routes, but also the value characteristics of Chang'an City of Tang Dynasty. Its cultural characteristics are both material and immaterial, tangible and intangible, dynamic and static aspects.

The archaeological sites in China are made up of earth, stone, wood and other natural materials, among which rammed earth material accounted for the majority. After years, most of them only have the underground rammed earth foundation, so the remains are extremely fragile, vulnerable to destruction and poorly preserved. At the same time, most of the sites are almost buried in the ground which result in weak readability. At the same time, its culture is far from the knowledge background of the general public in modern life, so the understanding of it is limited. In particular, it needs to be rediscovered by professional means such as archaeological investigation, studied, translated and interpreted before it is recognized by the public.

The site reflects the significance and wisdom of the construction of our ancestors, and is the spatio-temporal witness of the development and vicissitudes of man-land relationship. It is the symbol of the spirit, but also People's daily life, emotional link. Although the historical function of the site fade away, the site itself and the environment always maintain the continuity of space and time in the process of the development of human civilization, and it still continues to play a positive social role in the close integration of the present and the past.

Most important of all, the resources are vastly and unpredictably distributed, and conservation and development are closely linked. Sites buried in the ground often have huge potentials, so the period of archaeology, research and protection work is quite long. However, the protection of the site is closely related to the utilization of land resources, and is inseparable from the residents' life and production, urban and rural development, economic and cultural construction of the site. Especially in the rapid development of urbanization in China, the protection and management of large archaeological sites and their environment are facing unprecedented pressure. This contradiction is the reality that sites conservation and presentation need to face.

\subsection{The Breakthrough Solution}

For large archaeological sites as a whole, such a fragmented approach to understanding the site and the relatively isolated distribution of sites' presentation spots make the construction of interpretation facilities emphasize the visit to a single site rather than the correlation among the whole, which has become a relatively common reality. At the same time, in the face of the conservation and presentation of large archaeological sites, the operation is also a process of value evaluation, in which, the expression of the understanding and respect for the site, the value of the relationship between the whole and the part and the interpretation, should be considered as the focus of the operator at any time.

In order to convey the meaning behind these scattered sites to the public, it is not enough to focus only on the explanation of a particular place or area. A complete narrative text must be formed from the perspective of the urban ruins as a whole.

For Chang'an City of Tang Dynasty, there are objective conditions to realize this.

The rich undeveloped sites hidden beneath modern cities are confirmed by the checkerboard urban pattern recorded in historical geographic documents, which makes it possible to gain a relatively clear understanding of the overall pattern on the basis of only a few excavations. In historical geographic documents, the record of important buildings and their locations within Lifang (the basic unit), taking Lifang as the basic unit, makes about the location of memory and contact. Even if no site has been found, it can be located relatively accurately within the range of one sixteenth, one twelfth, one quarter or one square of one Lifang. This undoubtedly provides very favorable conditions for establishing the connection between place and time and historical events. The restoration of the city site pattern and the archaeological work on the Chang'an City Site in recent years make it possible for the layout of Chang'an City of Tang Dynasty to fall into a modern city.

In the study of spatial interpretation strategies, the most important point is that designers should do as much research as possible to understand the city, to understand how it was built and developed, how the past and the present correspond. The indepth study of urban text has become the most important part of the design strategy. The in-depth research is always the foundation of the authentic and credible interpretation content, and the category of research determines the depth and breadth of the possible contents provided by the interpretation (Wei Qing, 2015).

\section{URBAN TEXT INTERPRETATION}

To interpret urban text, we should first realize that urban growth is a continuous process, and the spatial structure of a city records the track of human activities and the historical context of urban development in its unique way. Historical cities have a social function of carrying on "Collective Memory" (Rossi, A, 1982) .

The founders of urban planning saw the city as a continuum of history and an environment connected to its wider area. The main determinants of urban transformation are heritage, memory and human association of spatial values (Geddes, P., 1915). In the practice of modern urban protection, planners are required to respect the historical form and the important connection between space and society, and protecting the social context of historical cities becomes one of the most important goals of planning (Bandarin, F.; Oers, R. van, 2012). Developed by modernism, another important thoughts, focus on the city's natural - the result of the historical process of laminated structure. This analysis method to dynamic urban space as the 
object, inspects each city landscape traces of society period, and reflects the society at that time the required form for research (Conzen, M. R. G., 2004), identified townscape is shaped by its true history.

Before coming up with a strategy, we should first understand how the urban space of Chang'an City of Tang Dynasty influenced the spatial structure of modern Xi'an city.

\subsection{To understand the city in terms of the axis and the continuation of the street}

After Chang'an City of Tang Dynasty destroyed, Xi'an city has been followed the former texture and pattern. Through analysis, we can see that since the Tang Dynasty continued to use the west and south palace walls and some gates of the Tang Imperial City, the continued use of gates such as Hanguang Gate, Zhuque Gate and Anshang Gate on the south wall, Shunyi Gate and Jingfeng Gate on the east and west walls limited the development of the main roads inside the city wall and indirectly controlled the pattern of roads outside the city wall, which is also the main reason that the pattern of Zhuque Avenue, Anshangmen Street, Chunmingmen-Jinguangmen Street and the Fourth East-west Street correspond to the pattern of the original Tang Dynasty. These important road positions are the core of the city planning of Tang Chang'an City.

Let's return to the order of city construction: starting from the second year of Kaihuang (582 AD), it took more than nine months to build the palace city and the imperial city. In the following year the emperor moved to the new capital. However, in $613 \mathrm{AD}$, part of the city wall was started to be built, then the overall pattern of the city was roughly accomplished. Due to the defense need of the imperial city, the wall in this section was found higher and stronger than the outer city wall. In contrast, the function of outer city wall is more inclined to define the boundary of the city and give consideration to the defense function. For at least 30 years, the city was deprived of walls. Less than five years after the wall was built, the dynasty changed. In $654 \mathrm{AD}, 41,000$ people were mobilized to build the capital city for 30 days. Emperor Xuanzong of Tang built the capital again in April, 730 AD.

We can also see the importance of the elements of urban pattern from the order of city construction. Ritual and imperial power are the core, so there were "Three Courts and Five Gates" ${ }^{1}$ System and the urban axis accompanied them. The initial form of the central axis is not the road, but the axis that dominates the overall situation in the plan of palace buildings.

Mr. Liang Sicheng once praised Chang'an City as a "planned city", and believed that such a plan had "reached the highest level of development in Chang'an of Tang Dynasty".

Compared with other cities in the same period and before, Chang'an City of Tang Dynasty was the only city that combined the palace axis with the central axis of the city and formed a perfect symmetry. That explains why it is the ideal city model of the Zhouli Kaogongji and why it is a model of mature Confucian urban civilization and urban structure (Xue Fengxuan, 2015).

${ }^{1}$ The "Three Courts and Five Gates" system is a palace system, derived from the rites of the Zhou Dynasty, which prescribes five gates for the emperor and three gates for the princes, symbolizing reverence for the order of rites. There are three courts for the emperor and the princes. In the Sui and Tang Dynasties, Taiji Palace of Chang'an City had five gates (Chengtian Gate, Taiji Gate, Zhuming Gate, Liangyi Gate, and Ganlu Gate) and three courts (Chengtian Gate, Taiji Hall, and Liangyi Hall.)
The central axis of ancient Chinese cities developed from the axis of architecture and became the organizer of urban space beyond the scope of the axis of architecture, carrying the ancient Chinese people's understanding of space and social order, and reflecting the inheritance of traditional Chinese culture (Zheng Wei, Ding Kangle, Li Jingsheng, 2008). Chang'an City of Tang Dynasty, as the defining period of axisymmetric urban space, was also the only capital city design case that realized complete symmetry in layout. The Daxing City of Sui Dynasty inherited the Ye City of Cao Wei Dynasty, Luoyang City of Northern Wei Dynasty, on the basis of former generation of capital planning experience, created a new system of capital. Since its establishing process in a reflection of both Confucianism and philosophies, it is referred to as the ideal city pattern since the Han Dynasty to perfect interpretation of the model.

This kind of exemplary urban space planning is unique in the history of China. It can be called one of the most unique cultural connotations of Chang'an of Tang Dynasty. It embodies the cosmic ideal, political ideal, social ideal and urban planning ideal of the Chinese nation. Therefore, the protection and interpretation of the pattern is one of the most important contents in the interpretation.

The axis is a spatial concept and a reflection of ideas -Symmetrical Balance, Balance between Yin and Yang, and the traditional Patriarchal System. The ritual of the palace extends into the urban space and is presented as a road outside the city gate, controlling the order of the whole city. Therefore, Zhuque Avenue corresponding to Chengtian Gate has become an etiquette street with a width of 155 meters, while the east-west street outside Chengtian Gate is 200 meters wide. In addition to safety concerns, the square has already exceeded the traffic demands of normal roads. Historical records also show that these spaces were also used as squares.

From the perspective of urban planning, urban axis plays a controlling role in urban spatial structure.

\subsection{Unconscious Succession}

At the end of Tang Dynasty, Chang'an City was ruined during wars. After Emperor Zhaozong of Tang moved the capital to Luoyang, Han Jian, the Jiedushi ${ }^{2}$ of Youguo Circuit, abandoned the outer city and rebuilt the imperial city ${ }^{3}$. It was referred to as "Han Jian New City" in history, and the city size was about one sixteenth of Chang'an City of Tang Dynasty.

During the Wudai, Song, Jin and Yuan Dynasties, the city continued to use the New City wall. The city axis is the main east-west street connected with Shunyi Gate and Jingfeng Gate of Tang Dynasty. With the development of urban functions, the government offices, schools, markets and some temple buildings were added, but the urban pattern remained as it used to be.

In the early Ming Dynasty, the king of Qin expanded the city. On the basis of the new city built by Han Jian, the city expanded by one third to the east and one third to the north, retaining the western and southern city walls of the original Imperial City of Tang Dynasty. Due to the expansion, the central axis of the city was moved from Zhuque Avenue to Anshangmen Street of

\footnotetext{
2 The Jiedushi was a title for regional military governors in China which was established in the Tang Dynasty and abolished in the Yuan Dynasty. The post of Jiedushi has been translated as "military commissioner", "legate", or "regional commander".

${ }^{3}$ Han Jian was the military governor of Youguo Circuit, which was headquartered at Chang'an.
} 
Tang Dynasty, which is now named Yongning Gate and Chang'an Road. The original gate is still in use. In the second year of Longqing (1568 AD), when the city wall was rebuilt, black bricks were built on the outer wall and the top of the city wall. The original loess structure was no longer used. In the north wall opened up the new Anyuan Gate, the east wall opened up the Changle Gate. It was not until the founding of the PRC that the Zhuque Gate and Hanguang Gate were reopened. However, as this city has experienced nearly four hundred years of development, in order to adapt to the existing urban roads, a new two gate location is not in full correspondence to the site of Tang Dynasty. As a result, with the opening of the new city gate, the Hanguang Road and Zhuque Street, which run through the city gate, were somewhat misplaced in spatial position with Hanguangmen Street and Zhuque Avenue of Tang Dynasty, but on the whole, they still maintained a parallel continuous relationship.

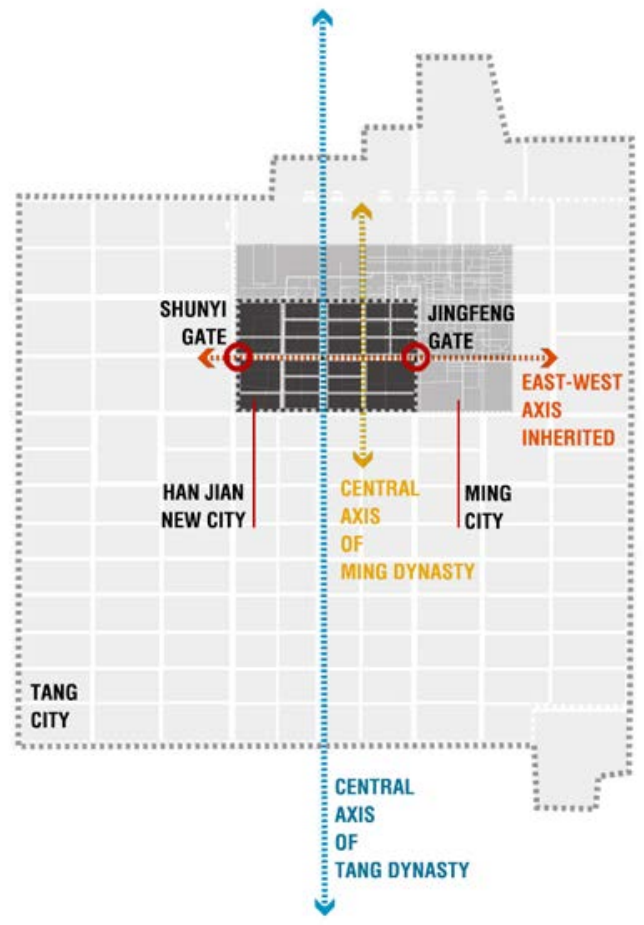

Figure 3. The inheritance of Chang'an City

\subsection{Conscious Conservation through Urban Planning}

The interesting thing about the city of Chang'an of Tang Dynasty is that when we trace its development history inside and outside the city walls of Ming Dynasty, we will find that inside the walls is the result of the accumulated development of the city since Tang Dynasty, while outside the walls is the reflection of the modern urban planning of Xi'an.

In the first round of master plan of Xi'an, which was prepared in 1952, the urban road system inherited the road pattern of Chang'an City of Tang Dynasty and Xi'an City of Ming Dynasty, the Main South Avenue, the Main North Avenue and their extended roads were taken as the central axis of the city. At that time, it was considered that the north of the city was not the main direction of urban space expansion due to the site of Chang'an City of Han Dynasty (and the unfavorable crossing of the railway). Xingqing Palace Park and Qujiang Lake have been seen in the planning.

From 1957 to 1963, with the awareness of the overall pattern, archaeologists carried out a large-scale survey of the city site, basically clear about the shape, structure, layout and scope of the site, and drew the measured map and preliminary restoration map of Tang Chang'an City Site of Tang Dynasty, which laid a solid foundation for the comprehensive study of the city site. After that, the urban planning of Xi'an took the archaeological pattern as a prerequisite factor for planning consideration. In the second round of master plan from 1980 to 2000, the preservation principles of "showing the grand scale of Chang'an City of Tang Dynasty, maintaining the strict layout of Xi'an in Ming and Qing Dynasties, and protecting the major sites of Zhou, Qin, Han and Tang Dynasties" were first determined. In the general drawing, the Chang'an City of Han Dynasty, Daming Palace, and the Tang City Wall Site Park in the south and west can be seen. In order to protect the historical and cultural heritage, large and medium-sized new industrial projects have been placed on the outskirts of the city. Roads still retain the checkerboard network framework in the first master plan. At this time, Xi'an has formed a "meter-shaped" external traffic structure, and the urban spatial structure and form of Xi'an have further developed along the single-center mode, and the city has presented a patchwork mode of expansion.

In the third round of master plan, although historical and cultural cities are placed in the first place and their importance is highlighted, the urban development space is limited due to the restrictions and constraints of the protection of large areas of historical and cultural sites within the planning scope. Although the planning has considered the change of the urban structure, due to the ubiquitous remains, some groups in the new planning are still close to the historical and cultural sites, which makes it difficult to realize the purpose of evacuation and does not improve the expansion of the spread pattern.

When the fourth round of master plan (2008-2020) was compiled, the contradiction between the old and new cities had become increasingly prominent. The topological relationship between urban construction and urban remains in Xi'an was like five open fingers infiltrating each other. In the early days of the city's development, the protection of historical sites in Xi'an has always been to give priority to any concession. Then, it has gone through several stages to preserve remains, such as the dormancy therapy of delimiting the area and negative protection, the passive restoration and reconstruction, and the active cultural industry revival to drive the surrounding construction. But by the end of the 20th century, the urban sprawl in Xi'an had reached a point where it was impossible to bypass the historic sites and had to face history head-on.
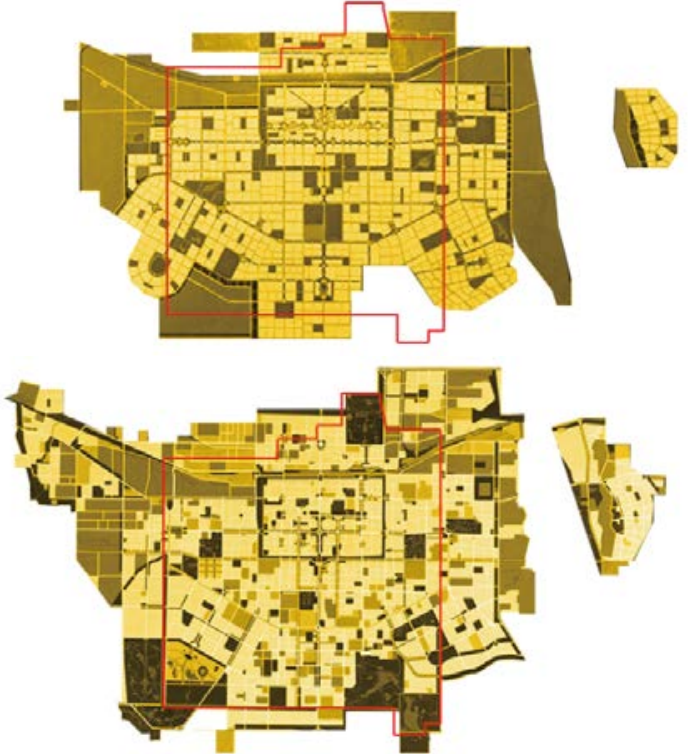

Figure 4. The master plans of Xi'an, 1958 vs 1980 


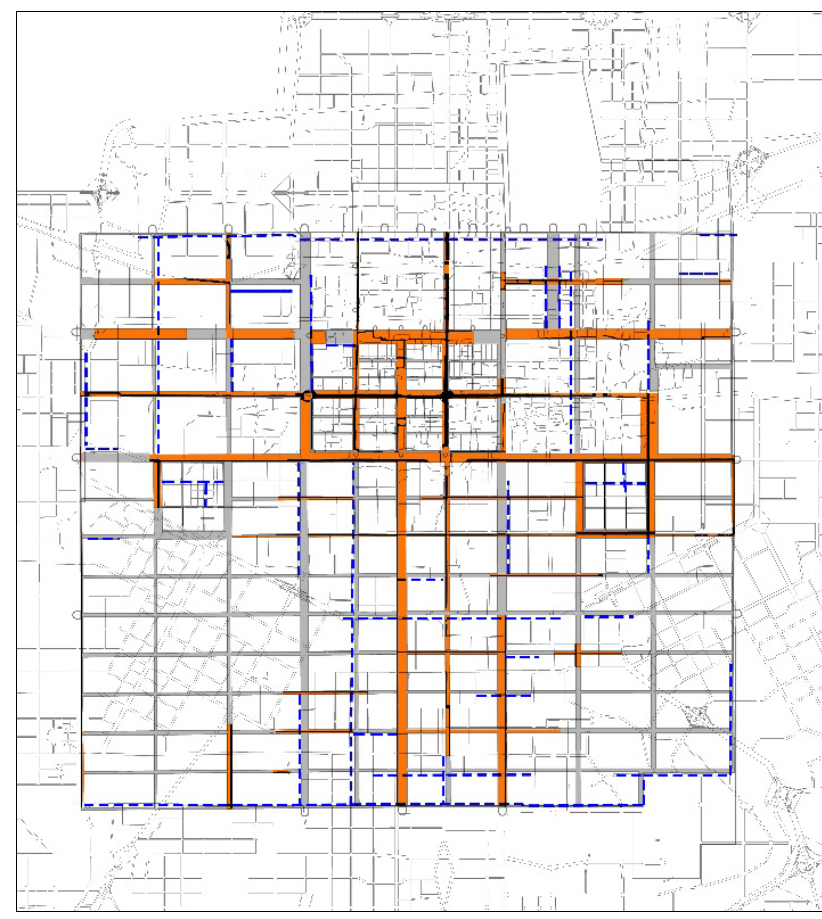

Figure 5. The Inheritance of the roads in modern Xi'an city from Chang'an City of Tang Dynasty

\section{STRAGEDIES}

\subsection{Construct the Presentation Framework}

As a technical guarantee, comprehensive conservation and management planning should first establish the idea of graded protection after grasping the information of the scope boundary, road system, functional zoning and important nodes of the city site, and having a real understanding and grasp of the structure, type, nature and characteristics of the large sites. The trenches and walls that constitute the boundary of the site, the roads and canals that constitute the veins of the site, and the key buildings that constitute the main parts of the site are regarded as important protection objects.

4.1.1 Show the Central Axis: Highlight the Zhuque Avenue and the gates on the axis to emphasis the depth of the whole sequence space.

4.1.2 Show the Boundary: Highlight the four corners of the Tang Chang'an City while protruding the gates, implementing the Tang City Wall Site Park step by step, emphasizing the continuity of the city wall and moats.

4.1.3 Show the Layout and Urban Elements: Including the palace city, the imperial city, the units (Lifang), the markets, the road and water network. Focus on the identification of corners, gates and other elements of the location and information. Present and prompt the spatial pattern of the roads which have a continuous relationship with Chang'an City of Tang Dynasty.

4.1.4 Construct the Site Signage System: Through setting up interpreting facilities and signboards throughout the city, a comprehensive and three-dimensional site interpretation system need to be formed to strengthen the interpretation of the value and connotation of the sites.

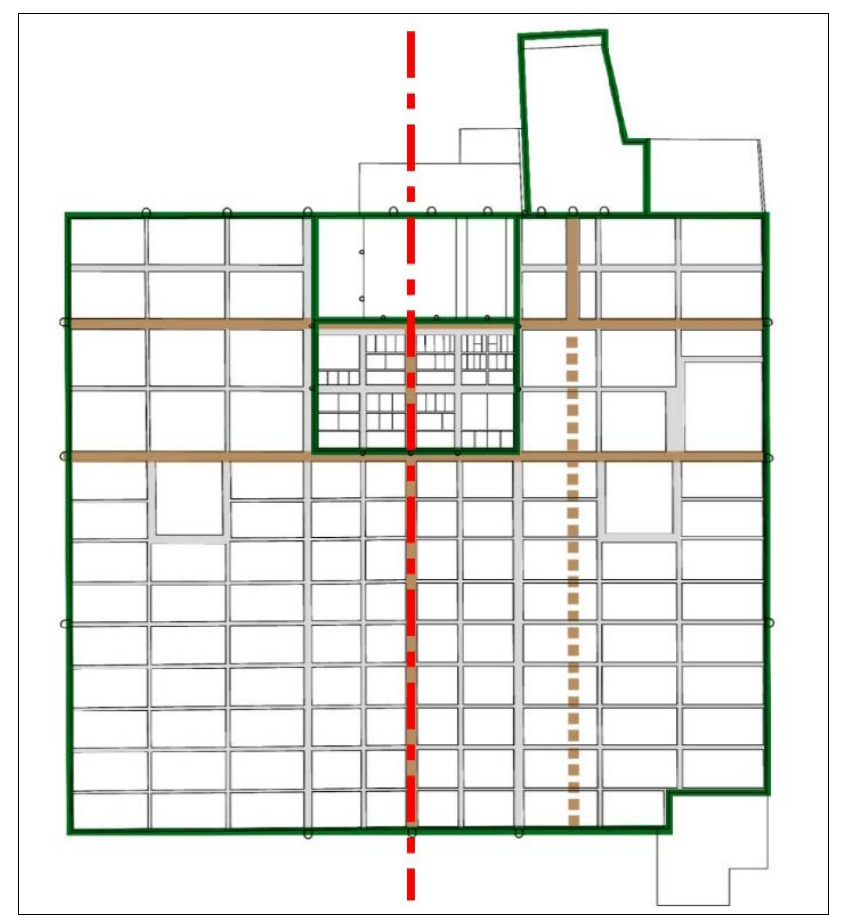

Figure 6. The central axis, the boundary, and the four main streets of Chang'an City of Tang Dynasty

4.1.5 Plan the Interpreting Route: The relevance and story of space and content of the site could be emphasized through the presentation themes, stories and routes. Strengthen the interpretation of the value connotation, historical background, value orientation and cultural characteristics of the site. Interprets the evolution of Chang 'an City from its original construction to its demise in Sui and Tang Dynasties, narrating the changes of history with time clues to continue the memory of the city through the relics of different periods.

\subsection{Further Emphasis on the Spatial Structure of the Site in Urban Planning}

The spatial and temporal elements should be constructed as a whole, highlighting the protection and restoration of topography and landscape, coordinating urban development, and building a spatial structure of "one axis, two rings, four streets, and multiple points", to awaken the urban pattern and spirit of Chang'an City of Tang Dynasty.

4.2.1 One Axis: The central axis of Chang'an City in Tang Dynasty could be shown by taking the sites of Mingde Gate, Zhuque Gate, Chengtian Gate, Xuanwu Gate, and Zhuque Avenue remains in Anren Block as nodes, and using modern urban roads as clues.

4.2.2 Two Rings: Outer City of Chang'an of Tang Dynasty To highlight the boundary primarily formed by the Tang City Wall Site Park, the four corners, gates, and part of the city wall remains;

City Wall of Xi'an Prefectural City in Ming and Qing Dynasties -With the existing walls of Ming and Qing Dynasties and parks around the city, the location, pattern and information of elements such as Taiji Palace of Tang Dynasty, Imperial City wall, gates, corners and inner streets could be located and presented. 
4.2.3 Four Streets: The four major streets which are inherited by modern urban city to be highlighted are Zhuque Avenue, the street connecting Chunming Gate and Jinguang Gate, east-west Street outside Chengtian Gate, Avenue outside Danfeng Gate. Besides, the 14 east-west roads and 11 southnorth roads network structure of Chang'an City of Tang Dynasty could be hinted on the main four streets.

4.2.4 Multiple Points: Combined with urban public space and sign interpretation facilities, the location, scale, historical events and other information should be interpreted, and fit into urban roads, squares, green spaces, parks and other functions to improve the quality of space.

\section{CONCLUSIONS}

There are a large number of potential remains in Chang'an City of Tang Dynasty, which can be explained because of its unique urban planning and construction in history, the inheritance of the original spatial pattern of urban construction in later generations, the special recording methods of historical and geographical documents, especially the exploration and positioning of the overall pattern of the city site since 1957. None of these conditions is dispensable. They enable the interpretation and presentation of Chang'an City of Tang Dynasty to establish the connection between site and historical memory with relatively accurate spatial positioning, when most of the ruins were destroyed by urban construction and the archaeological work was limited by construction while only a few archaeological excavations were done.

For city remains like Chang'an of Tang Dynasty, in order to establish the relationship between space and historical sites, what we should do is to conduct in-depth research, expand the content of its settings, fully understand the context, and endue the interpretation of the content with a real and credible basis.

The civilization charm and urban ideal of Tang Dynasty have an eternal significance after the demise of the dynasty, which drives the later generations to continuously study the footprints of predecessors and interprets the connotation of culture in a unique way. Today, our cognition of the site is no longer confined to archaeological materials, historical information, evolutionary evidence, and museum exhibits, but also includes the understanding, comprehension and re-transmission in situ. In this way, the operation of conservation and presentation is not just the preservation of the object or the reproduction of information. It integrates the ancient and modern vision, awakens the sleeping memory and reinvigorates the site and the city by constantly acknowledging, grasping and inducing meaning.

The interpretation of Chang'an City Site of Tang Dynasty lies in the multi-level goal, diversified answers and dynamic process, which requires us to inherit the cultural significance, interpret the role of the origin of civilization with the subjective thinking, and provide the public a better life and longing. Undoubtedly, this is a huge system and network. What remains unchanged is the millennium pledge, "Established here, the great dynasty will be perpetually stable, and its infinite undertakings will never be completed." 4

\section{REFERENCES}

Dong Jianhong, 2013. Planning of Chang'an City in Sui and Tang Dynasties. In: The Chinese City Reader. World Book Inc, Beijing, pp. 46-53.

UNESCO, 2014. Nomination File of "Silk Roads: the Routes Network of Chang'an-Tianshan Corridor". https://whc.unesco.org/en/list/1442/

Zhang Jianlin, Gong Guoqiang, 2016. Urgent! The Last Chance to Protect the Chang'an City Site of Sui and Tang Dynasties. https://mp.weixin.qq.com/s?_biz=MjM5NzUzNjE2MA==\&mi

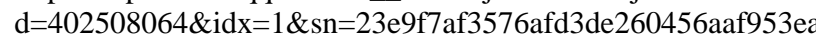

Wei Qing, 2015. Interpretation and Presentation of Heritage: the Last Link Connecting the Starting Point. World Heitage, 11, pp. 22-23.

Rossi, A., 1982. The Architecture of the City. MIT Press, Cambridge.

Bandarin, F.; Oers, R. van, 2012. The Historic Urban Landscape: Managing Heritage in An Urban Century. Wiley Blackwell, Chichester, West Sussex, UK ; Hoboken, NJ: chapter 4.

Geddes, P., 1915. Cities in Evolution: An Introduction to the Town Planning Movement and to the Study of Civics. Williams, London.

Conzen, M. R. G., 2004. Thinking about Urban Form: Papers on Urban Morphology, 1932-1998. Peter Lang, Oxford.

LI Chuanbin, 2002. Study on the Evolution Process of Xi'an Urban Spatial Structure. MA thesis. Northwest University, Xi'an.

Xue Fengxuan, 2015. The Evolution of Chinese Cities and their Civilization. World Book Inc, Beijing.

Zheng Wei, Ding Kangle, Li Jingsheng, 2008. Historical Investigation on the Design of the Central Axis of Ancient Chinese Cities. Architect, 2008(04), pp. 91-96

Liu Yi, Lei Yaoli, 2018. Intergrated Research on Constitution of Cultural Route under the Vision of Intangible Culture-Case Study on Beginning Section of the Silk Road (in Shaanxi Province). Research on Heritages and Preservation, 3(8) , pp. 24-26.

\footnotetext{
${ }^{4}$ From Book of Sui written by Wei Zheng et al. of Tang Dynasty.
} 